\title{
The COST system of networking in the field of food and agriculture research
}

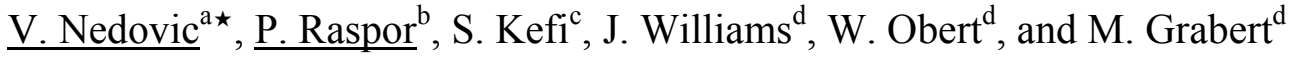 \\ ${ }^{a}$ Dept. of Food Technology and Biochemistry, Faculty of Agriculture, University of \\ Belgrade, Belgrade, Serbia, vnedovic@agrifaculty.bg.ac.yu \\ ${ }^{b}$ Food science and technology department, Biotechnical Faculty, University of Ljubljana, \\ Ljubljana, Slovenia, peter.raspor@bf.uni-lj.si \\ ${ }^{\mathrm{c}}$ Agriculture, Forestry \& Veterinary Research Group, TUBITAK, Ankara, Turkey, \\ servet.kefi@tubitak.gov.tr \\ dCOST Office, Brussels, Belgium, jwilliams@cost.esf.org, wobert@cost.esf.org, \\ mgrabert@cost.esf.org \\ ${ }^{\star}$ corresponding author
}

\begin{abstract}
COST is an intergovernmental framework for European Co-operation in the field of Scientific and Technical Research, allowing the co-ordination of nationally funded research on a European level. COST Actions cover basic and pre-competitive research as well as activities of public utility. The aim of the paper is to present the COST system of networking in the field of Food and Agriculture research and to give some advices how to prepare and present the new COST Action/Project, and also how to join an ongoing COST Action/Project.
\end{abstract}

COST is an intergovernmental framework for European Co-operation in the field of Scientific and Technical Research, allowing the co-ordination of nationally funded research on a European level [1]. COST Actions cover basic and pre-competitive research as well as activities of public utility. The goal of COST is to ensure that Europe holds a strong position in the field of scientific and technical research for peaceful purposes, by increasing European co-operation and interaction in this field. COST has clearly shown its strength in non-competitive research, in pre-normative co-operation and in solving environmental and cross-border problems and problems of public utility. Ease of access for institutions from non-member countries also makes COST a very interesting and successful tool for tackling topics of a truly global nature. To emphasise that the initiative came from the scientists and technical experts themselves and from those with a direct interest in furthering international collaboration, the founding fathers of COST opted for a flexible and pragmatic approach. COST activities have in the past paved the way for Community activities and its flexibility allows COST Actions to be used as a testing and exploratory field for emerging topics. The member countries participate on an "à la carte" principle and activities are launched on a "bottom-up" approach. One of its main features is its built-in flexibility. This concept clearly meets a growing demand and in addition, it complements the Community programmes. COST has developed into one of the largest frameworks for research co- 
operation in Europe and is a valuable mechanism co-ordinating national research activities in Europe [1].

COST Food \& Agriculture is one of the 9 COST domains. It covers all aspects of research in the field of agricultural and food sciences in its widest sense [2]. This naturally encompasses a very wide number of subjects, and relates to a large number of areas of human activity. It includes all aspects of research of food and non-food chains, including primary agricultural and horticultural production and processing, development and downstream processes for edible and non-edible production derived from agriculture in its widest sense. The domain deals with both plant and animal sciences and food sciences, and the technologies relevant to these.

The primary aim of the Domain is to encourage networking of research in any field linked to these activities as well as the related demands and needs [2]. It covers the following areas:

$\leftrightarrow$ The Biological Functions of Organisms comprises biological, veterinary, animal, plant, microbiological, and soil sciences, or any other fundamental discipline related to food, agriculture \& fisheries.

$\Leftrightarrow$ Human Nutrition and the Food Chain comprises the entire food chain leading to nonprocessed, semi-processed and processed foods and encompasses food and feed quality, food safety, nutritional and consumer issues. It includes all the processes and techniques used in food technology that are needed to bring food to the consumer's fork.

$\Leftrightarrow$ Agriculture as a Human Activity addresses socio-economic aspects of food and agriculture and other relevant concerns, such as the relationships between agriculture, rural economy and rural development. Societal issues concerned with animal health (disease prevention in animals and people) and animal welfare are also included.

$\stackrel{\leftrightarrow}{\leftrightarrow}$ Agriculture and Environment includes issues such as sustainability, natural resources and conservation, biodiversity, biosafety, bioremediation, and bioenergy. It also addresses changes in European agriculture under the influence of major issues such as global warming, world trade patterns and energy scarcity.

The Domain actively seeks innovative and interesting proposals even if they may not at first sight fit neatly into a traditional category of research in food and agriculture. And since food and agriculture involve so many scientific disciplines, it is anticipated that successful proposals will vary widely in nature from closely focussed topics of a fundamental nature using the most innovative and up-to-date techniques (such as tools for genomics, proteomics and metabolomics) to multidisciplinary projects having a more holistic approach (such as new farming systems for the production of quality food)

COST Food \& Agriculture is managed by the COST domain committee on Food \& Agriculture (FA DC) to which all COST member states can nominate national representatives. The FA DC assesses proposals for new Actions, monitors current Actions and evaluates finished Actions. The FA DC also works closely with other COST domain committees, and with other organisations (such as the European Commission (Framework Programme), the ESF, EUREKA and INTAS to promote collaboration and synergy and, where appropriate, to encourage interdisciplinary approaches. 
Some of the important research topics that are currently running inside the COST Food \& Agriculture Domain are as follows:

- Animal and plant genomics

- Animal health and welfare

- Animal production

- Early determinants of meat quality

- Exploitation of enzymes in processing

- Food matrices and flavour

- Foodborne zoonoses

- Health implications of dietary amines

- Novel biotechnologies

- Pest control

- Plant health

- Plant production

- Plant tissue culture

- Quality food and health promoting components

- Quality of agricultural products

- Soil science

- Sustainable agricultural systemsTh

- Thermal Processing

\section{References}

[1] http://www.cost.esf.org

[2] http://www.cost.esf.org/index.php?id=50 